See Article page e191.

\section{Commentary: There is never "best," only "better"}

\author{
Song Wan, MD, FRCS
}

Around 13 years ago, a world-renowned expert in mitral valve repair was invited to deliver a lecture on tricuspid valve surgery at an international symposium in Hong Kong. He began by stating that "the next slide summarizes our current knowledge about tricuspid regurgitation (TR) and the best surgical strategies to repair it." One second later, he caused an uproar in the room-the slide was blank, without a single word or figure.

Despite this apparent exaggeration, the tricuspid valve remained an almost "forgotten valve" until recently. During the past decade, we have witnessed a substantial increase in the volume of surgical tricuspid valve interventions worldwide, the majority of which involve repairs made concomitantly during other cardiac procedures. ${ }^{1,2}$ This dramatic trend has been based on improvements in knowledge and fundamental consensuses, including (1) more than $80 \%$ of significant TR cases are functional and secondary to tricuspid annular dilation; (2) significant TR is associated with a poor prognosis, independent of age, left and right ventricular function, and right ventricular size; (3) tricuspid annular dilation is an ongoing process. Moreover, untreated TR often progresses, and (4) the correction of left-sided disease alone may not prevent further progression of TR. ${ }^{3} \mathrm{~A}$ convincing body of evidence implies that relative to tricuspid valve replacement, tricuspid repair is associated not only with lower rates of postoperative morbidity and mortality, but also with better long-term survival. ${ }^{1-3}$ More importantly, the results of tricuspid annuloplasty with a ring appear to be much more durable than those of annuloplasty without a ring. ${ }^{4}$ Few clinicians would therefore now disagree that the tricuspid valve should be repaired with an annuloplasty ring whenever this is indicated and feasible.

\footnotetext{
From the Division of Cardiothoracic Surgery, Department of Surgery, The Chinese University of Hong Kong, Prince of Wales Hospital, Hong Kong, China. Disclosures: Author has nothing to disclose with regard to commercial support. Received for publication Oct 15, 2019; revisions received Oct 15, 2019; accepted for publication Oct 15, 2019; available ahead of print Oct 31, 2019.

Address for reprints: Song Wan, MD, FRCS, Division of Cardiothoracic Surgery, The Chinese University of Hong Kong Prince of Wales Hospital, 30-32 Ngan Shing St, Sha Tin, New Territories, Hong Kong, China (E-mail: swan@surgery.cuhk.edu. hk).

J Thorac Cardiovasc Surg 2021;161:e211-2

0022-5223/\$36.00

Copyright (C) 2019 by The American Association for Thoracic Surgery https://doi.org/10.1016/j.jtcvs.2019.10.083
}

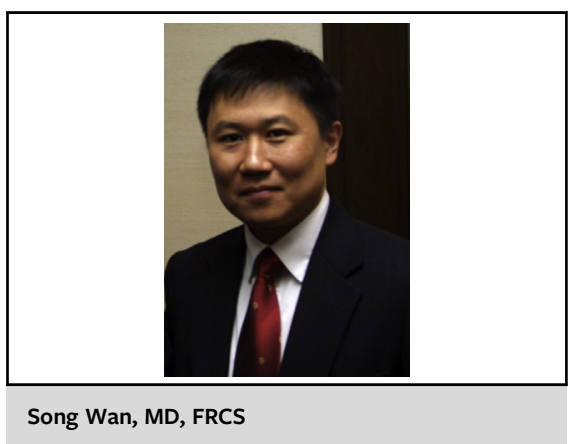

\author{
CENTRAL MESSAGE \\ Despite searches for the holy \\ grail of tricuspid repair ring, it is \\ unlikely for one ring to fit all pa- \\ thologies. For any specific pa- \\ tient, a "better" option among \\ rings should always be \\ considered.
}

Given this background, the report by Malinowski and colleagues ${ }^{5}$ in this issue of the Journal is extremely timely and relevant. Overall, their observations were quite logical and expected; specifically, the rigid non-planar Contour ring (Medtronic, Minneapolis, Minn) provided superior maintenance of the 3-dimensional (3D) geometry when compared with the flexible Duran ring (Medtronic) and hybrid Tri-Ad ring (Medtronic), whereas the latter 2 rings better preserved annular contraction and dynamics. Interestingly, Malinowski and colleagues ${ }^{5}$ selected 3 different but representative rings produced by the same company, possibly to avoid a potential conflict of commercial interests.

Indeed, several previous experiments of the mitral valve had been conducted with a similar large animal model. Nonetheless, these findings by Malinowski and colleagues ${ }^{5}$ reveal that the theories developed from mitral research might not always be applicable to the tricuspid valve. For instance, a flexible ring (or even an incomplete flexible band ${ }^{6}$ ) could maintain the native 3D saddle shape of the mitral valve but was apparently unable to maintain this shape in the tricuspid position. ${ }^{5}$ Moreover, it might not be ideal to choose a "saddle ring" for mitral repair in patients with a short duration of valvular disease (such as that secondary to endocarditis) who had maintained a normal native mitral geometry. ${ }^{7}$ Instead, a semirigid ring may better preserve both the mitral 3D geometry and the annular contraction and dynamics. ${ }^{7,8}$ It remains to be determined, however, 
whether this principle can also be applied to the tricuspid valve. In particular, it might be interesting to explore the use of a universally semirigid, nonplanar tricuspid ring (ie, different with the "hybrid" design of the TriAd ring) rather than a completely rigid ring (eg, the Contour ring).

Although the effects of maintaining the 3D geometry and annular dynamics on the durability of tricuspid valve repair deserve further investigation in clinical settings, the potential complications associated with different annuloplasty rings should never be overlooked. For example, a previous study of annuloplasty with a downsized rigid, nonplanar tricuspid ring reported a postoperative permanent pacemaker implantation rate of $10 \% .{ }^{9}$ Even without downsizing, the current study by Malinowski and colleagues ${ }^{5}$ showed that $20 \%$ of animals in the Contour group required pacing after ring annuloplasty. The surgeon must balance the potential long-term benefit of preserving the nonplanar 3D geometry after tricuspid valve repair with the corresponding risk of permanent pacemaker implantation when selecting a ring for each individual patient. This decision is particularly important, because some available rings, such as the TriAd ring, feature a specific design intended to avoid injury to the conduction system. For example, in my personal series of 112 consecutive patients to date undergoing tricuspid annuloplasty with the TriAd ring, the incidence of new-onset complete atrioventricular block remains at zero.

Taken together, this elegant study by Malinowski and colleagues ${ }^{5}$ has triggered additional research questions, including queries about the precise influence and quantification of nonplanar 3D geometry and the role of annular dynamics in the selection of a tricuspid annuloplasty ring. At least one aspect is clear; namely, it is unlikely that one "best ring" fits all pathologies and all patients. Rather, a "better" choice among the available rings should always be considered and evaluated for each individual patient with a specific disease.

\section{References}

1. Kilic A, Saha-Chaudhuri P, Rankin JS, Conte JV. Trends and outcomes of tricuspid valve surgery in North America: an analysis of more than 50,000 patients from the Society of Thoracic Surgeons database. Ann Thorac Surg. 2013;96:1546-52; discussion 1552.

2. Alqahtani F, Berzingi CO, Aljohani S, Hijazi M, Al-Hallak A, Alkhouli M. Contemporary trends in the use and outcomes of surgical treatment of tricuspid regurgitation. J Am Heart Assoc. 2017;6:e007597.

3. Nishimura RA, Otto CM, Bonow RO, Carabello BA, Erwin JP III, Guyton RA, et al; American College of Cardiology/American Heart Association task force on practice guidelines. 2014 AHA/ACC guideline for the management of patients with valvular heart disease: a report of the American College of Cardiology/ American Heart Association task force on practice guidelines. J Am Coll Cardiol. 2014;63:e57-185. Erratum in: J Am Coll Cardiol. 2014;63:2489.

4. Parolari A, Barili F, Pilozzi A, Pacini D. Ring or suture annuloplasty for tricuspid regurgitation? A meta-analysis review. Ann Thorac Surg. 2014;98: 2255-63.

5. Malinowski M, Jazwiec T, Quay N, Goehler M, Rausch MK, Timek TA. The influence of tricuspid annuloplasty prostheses on ovine annular geometry and kinematics. J Thorac Cardiovasc Surg. 2021;161:e191-207.

6. Gillinov AM, Cosgrove DM III, Shiota T, Qin J, Tsujino H, Stewart WJ, et al. Cosgrove-Edwards annuloplasty system: midterm results. Ann Thorac Surg. 2000;69: 717-21.

7. Wan S, Lee AP, Jin CN, Wong RH, Chan HH, Ng CS, et al. The choice of mitral annuloplastic ring-beyond "surgeon's preference". Ann Cardiothorac Surg. 2015;4:261-5.

8. Bouchez S, Timmermans F, Philipsen T, François K, Bové T. Comparison of the sustainability of mitral annular dynamics between two semi-rigid annuloplasty devices. Eur J Cardiothorac Surg. February 15, 2019 [Epub ahead of print].

9. Maghami S, Ghoreishi M, Foster N, Dawood MY, Hobbs GR, Stafford P, et al. Undersized rigid nonplanar annuloplasty: the key to effective and durable repair of functional tricuspid regurgitation. Ann Thorac Surg. 2016;102: $735-42$. 